\title{
Association between circulating leptin concentration and G-2548A gene polymorphism in patients with breast cancer: a meta-analysis
}

Ji-Qing Hao, Qian-Kun Zhang, Yi-Xin Zhou, Li-Hao Chen, Peng-Fei Wu

Department of Oncology, the First Affiliated Hospital of Anhui Medical University, Anhui, China

Submitted: 6 February 2018

Accepted: 15 April 2018

Arch Med Sci 2019; 15, 2: 275-283

DOI: https://doi.org/10.5114/aoms.2018.75638

Copyright $\odot 2018$ Termedia \& Banach

\section{Abstract}

Introduction: The aim of this meta-analysis was to summarize the evidence on the serum/plasma leptin concentrations in breast cancer (BC) patients, as well as the associations between leptin $G-2548$ A gene polymorphisms and susceptibility to BC.

Material and methods: Potentially relevant studies about serum/plasma leptin levels and leptin G-2548A gene polymorphism were selected using the electronic databases PubMed, EMBASE and The Cochrane Library (from January 11995 to Jun 30 2017, no language restrictions). The potential sources of heterogeneity were assessed by the $Q$ statistic and quantified using $l^{2}$; publication bias was qualitatively assessed by funnel plot and quantitatively assessed by Egger's linear regression test.

Results: A total of 1141 articles were retrieved after database searches, and 27 studies with 9516 subjects (4542 BC patients/4974 controls) were finally included. The results indicated that BC patients had significantly higher leptin levels compared with healthy controls $(S M D=1.65,95 \% \mathrm{Cl}$ : $1.21-2.09, p<0.001$ ), but there was no association between leptin $G-2548 \mathrm{~A}$ polymorphism and $B C(O R=1.05,95 \% \mathrm{Cl}: 0.80-1.39, p=0.722)$. Subgroup analyses demonstrated increased leptin levels in $B C$ patients of different region, race, body mass index and waist circumference.

Conclusions: Our results revealed a significantly higher leptin level in $\mathrm{BC}$ patients than in healthy controls, but no association between leptin $G-2548 \mathrm{~A}$ polymorphism and BC susceptibility was found.

Key words: breast cancer, leptin, gene polymorphism, meta-analysis.

\section{Introduction}

Breast cancer (BC) is the most common tumor among women. Although the mortality rate is decreasing mainly due to early diagnosis and improved therapeutic management, it remains the most common cause of cancer-related death in women [1, 2]. The carcinogenesis of $B C$ is multi-factorial, with early menarche, late full-term pregnancy, late menopause, and postmenopausal obesity all having been recognized as risk factors for $\mathrm{BC}[3,4]$.

Leptin, as a 167 amino acid polypeptide, was first reported as a regulator of food intake, metabolic rate and reproductive function, but recent

\author{
Corresponding author: \\ Dr. Ji-Qing HaO \\ Department of Oncology \\ The First Affiliated Hospital \\ of Anhui Medical University \\ Hefei 230022, China \\ Phone: +860551 62923612 \\ E-mail: ayfy_hjq@163.com
}


studies have demonstrated its multi-functional role in immunity, cell proliferation, inflammation, etc. A growing number of studies have suggested that leptin may be involved in the initiation and progression of human cancers $[5,6]$. Leptin is required for normal mammary gland development and lactation. Nevertheless, leptin may also contribute to mammary tumorigenesis. It is expressed in malignant epithelial cells of the breast $[7,8]$ and seems to be associated with stimulation of the growth of $B C$ cells $[9,10]$. There is a positive correlation between serum leptin levels and its mRNA level in the tumor. Moreover, individuals with an elevated serum leptin level might be at a higher risk of BC [11]. Tessitore et al. [11] and Chen et al. [12] reported positive correlations between serum leptin expression and $\mathrm{BC}$ risk, whereas other investigators did not find this relationship $[13,14]$.

Several leptin and leptin-receptor gene polymorphisms have been studied in BC patients among different populations. It was found that subjects carrying the leptin G-2548A (rs7799039) gene polymorphism had an increased risk for breast carcinoma $[15,16]$. Nevertheless, some studies reported that leptin G-2548A gene polymorphism was not associated with susceptibility to $\mathrm{BC}$ [17-19].

The results regarding leptin concentration and leptin -2548 G/A gene polymorphism association with $\mathrm{BC}$ are still inconclusive. Hence, we conducted a comprehensive review and meta-analysis. The main goal of this study was to find correlations between circulating leptin and breast cancer (BC), and between polymorphism G2524A and susceptibility to BC.

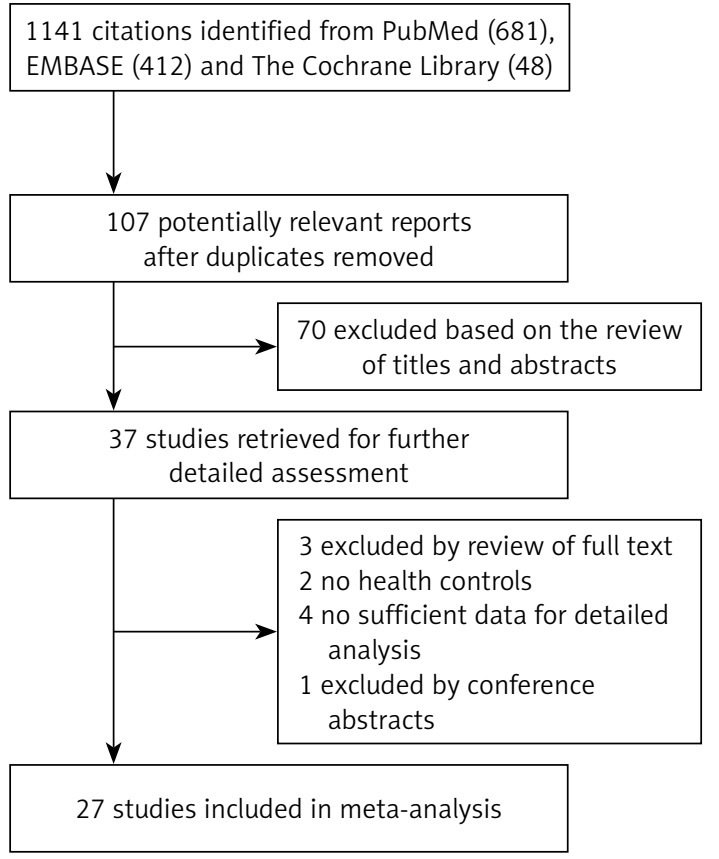

Figure 1. Flowchart of selected articles

\section{Material and methods}

\section{Search strategy}

We searched for related studies electronically in PubMed, EMBASE and The Cochrane Library databases (from January 11995 to Jun 30 2017, no language restrictions). For BC patients and healthy controls, the detection of leptin concentration was performed using serum or plasma blood samples. The keywords were searched in all fields: "breast cancer", "breast carcinoma", "breast neoplasm", "breast tumor", "leptin”, “adipokines”, "leptin G-2548A", "rs7799039", "gene polymorphism”. Variants of keywords were also used for the literature search. In addition, reference lists from full texts also were checked to identify other potentially missing eligible articles. No method restrictions were applied; the articles from all countries were accessible.

\section{Inclusion criteria and exclusion criteria}

Studies were retained in this meta-analysis if they met the following inclusion criteria: (1) consisted of original research (including case-control, cohort or cross-sectional studies) published in a peer-reviewed journal; (2) had information about leptin concentration for both BC patients and age- and sex-matched normal controls; (3) studied leptin G-2548A (rs7799039) gene polymorphisms in case and control groups; (4) publications in English. If more than one article was reported from the same study, only the most eligible one was included in the present study, considering data integrity and availability.

Studies were excluded if they reported ambiguous eligibility criteria, patients with other carcinomas, as well as patients who were pregnant, nursing, or taking any drug known to elevate or inhibit circulating leptin levels. The study selection process is presented in Figure 1.

\section{Data extraction}

We used standardized forms to extract data from each selected study, including the following variables: primary author name, year of publication, country, study sample size, mean and standardized difference (SD) of leptin levels and the genotype and allele frequencies of the leptin G-2548A gene polymorphisms. If original data of articles were not available, we contacted the corresponding authors for additional information.

\section{Quality evaluation of the literature}

The quality of each included study was evaluated by two independent investigators (Ji-Qing Hao, Qian-Kun Zhang) using a modified Newcastle-Ottawa Scale (NOS). In case of disagreement during 
the process of quality evaluation, a third investigator (Yi-Xin Zhou) was consulted.

\section{Statistical analysis}

Related data were synthesized with the standardized mean difference (SMD) and its 95\% confidence interval $(\mathrm{Cl})$ to calculate the pooled estimation of leptin levels between BC patients and control subjects. Odds ratios (ORs) and their 95\% Cl were calculated for the evaluation of leptin G-2548A gene polymorphisms between two groups by using: 1) allelic contrast, 2) recessive models, 3) dominant models, and 4) homozygote contrast of the G-2548A gene polymorphisms [15]. Cochran $Q$ statistics was conducted to evaluate the heterogeneity between studies, then quantified with $R^{2}\left(I^{2}=((Q-d f) / Q) \times 100 \%\right)[20]$, which were used to estimate the effect of heterogeneity among studies [21]. The $l^{2}$ takes values from 0 and $100 \%\left(I^{2}=0-50 \%\right.$, no or moderate heterogeneity; $l^{2}>50 \%$, significant heterogeneity). Given the considerable heterogeneity, we completed the analyses with a random-effect model. Otherwise, a fixed-effect model was applied for further analyses. Publication bias was evaluated by a funnel plot and Egger's linear regression test. Forest plots were used to depict the results graphically, and Egger's linear regression test was used to statistically detect publication bias [22]. If bias was found, additional tests were applied. To explore the between-study heterogeneity, subgroup analysis was conducted according to the stratification of region, race, body mass index (BMI), waist circumference (WC) and measurement type. All statistical analysis was performed using Stata 12.0 software (Stata Corporation, College Station, Texas, USA).

\section{Results}

\section{Basic characteristics of included studies}

Our search yielded 1141 relevant articles by the initial search strategy, and 27 articles were ultimately included in this meta-analysis according to the rigid inclusion and exclusion criteria. The final 27 studies included 9516 subjects (4542 BC patients/4974 controls). The baseline characteristics of the 21 incorporated studies regarding circulating leptin concentration in this meta-analysis are displayed in Table I [11, 12, 14, 17, 23-39], and the basic characteristics of the 7 included studies for G-2548A gene polymorphism are shown in Table II [15-19, 40, 41]. All the included studies had a case-control design and a clear diagnostic method for BC. The measurement types for leptin concentrations were as follows: 14 studies measured by enzyme-linked immunosorbent assay (ELISA); 7 studies measured by radioimmunoassay (RIA).
The mean frequency of the A allele was $46.6 \%$ among all controls, and $49.3 \%$ in all the patients with BC. The age and sex distribution between BC patients and control groups were comparable in each included study. Study quality assessments for all included studies were appraised using the NOS, and the NOS scores are displayed in Tables I and II, of which most of the studies had high quality scores of 5 to 8 stars.

\section{Meta-analysis results \\ Meta-analysis of circulating leptin level in $\mathrm{BC}$ patients compared to controls}

The pooled results of circulating leptin concentration indicated that there was a significantly elevated leptin level in BC patients compared to healthy controls (SMD $=1.65,95 \% \mathrm{Cl}: 1.21-2.09$, $p<0.001$ ) (Figure 2). Subgroup analyses suggested that region, race, BMI, WC and measurement type were associated with leptin in BC patients (Table III).

\section{Meta-analysis of leptin G-2548A gene polymorphisms and susceptibility to BC}

No significant association between the leptin G-2548A gene polymorphism and BC was found by using the allele contrast, recessive, dominant or homozygote models in all study subjects (OR for $\mathrm{A}$ allele $=1.05,95 \% \mathrm{Cl}: 0.80-1.39, p=0.722$ ) (Figure 3, Table IV). However, when compared to the other groups, we found that there was a higher prevalence for A allele frequency $(81.3 \%)$ in controls from Asia, as well as a higher A allele frequency (69.3\%) in Asian BC patients (Table V).

\section{Heterogeneity}

In the current study, the pooled analysis regarding circulating leptin levels showed marked heterogeneity $\left(I^{2}=98.00 \%, p<0.001\right)$ (Figure 2 ). Between-study heterogeneity was found when analyzing leptin $G-2548 \mathrm{~A}$ gene polymorphisms in $\mathrm{BC}\left(I^{2}=83.30 \%, p<0.001\right)$ (Figure 3$)$. Thus, a random effect model was conducted to pool the effect size both on circulating leptin concentration and leptin G-2548A gene polymorphisms in this meta-analysis.

\section{Publication bias}

The funnel plot for circulating leptin level showed a slightly asymmetrical distribution, and Egger's linear regression test revealed the existence of a significant publication bias $(p=0.006)$ (Figure $4 \mathrm{~A}$ ). Then, Duval's trim and fill method was applied to evaluate the asymmetry of the funnel plot and the potential publication bias risk. After 6 imputed filled values were filled, the results 


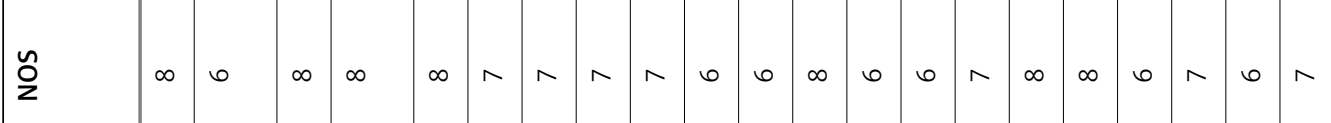

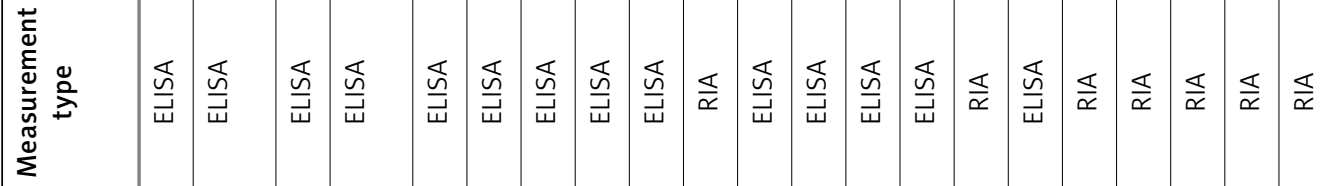

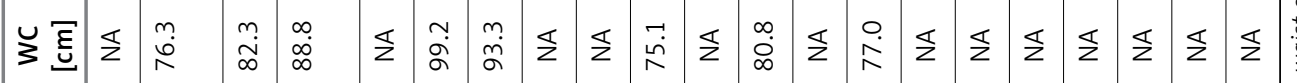

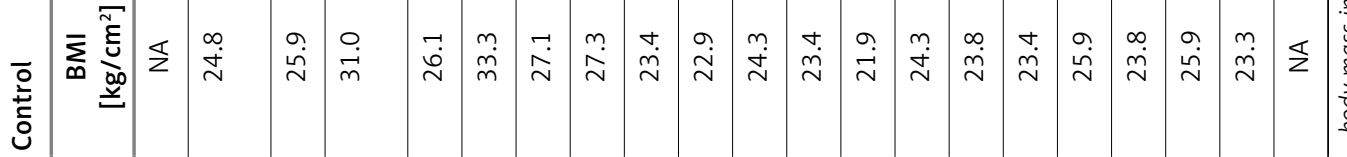

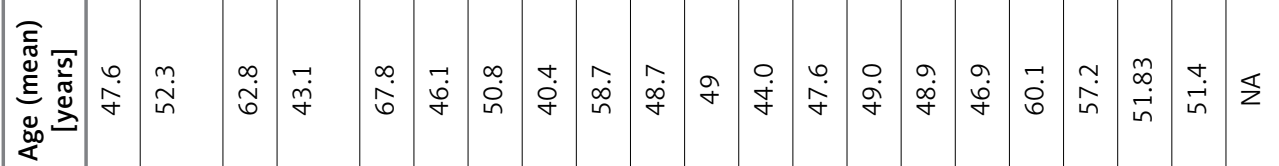

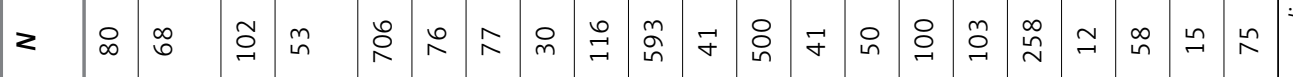

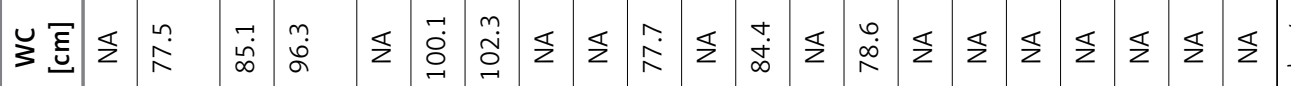

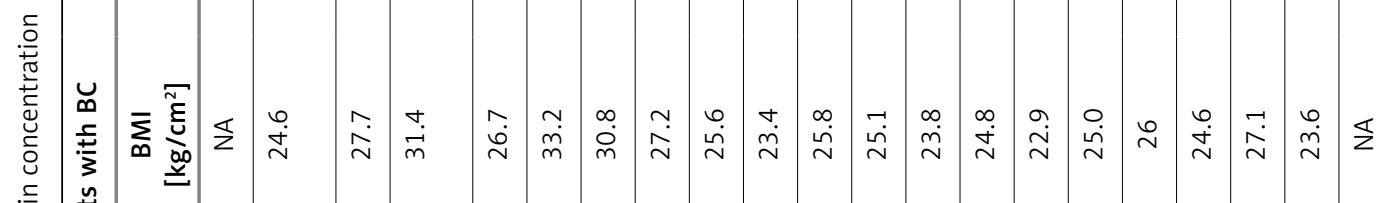

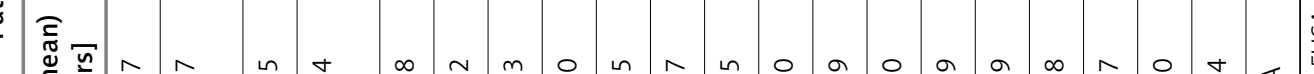

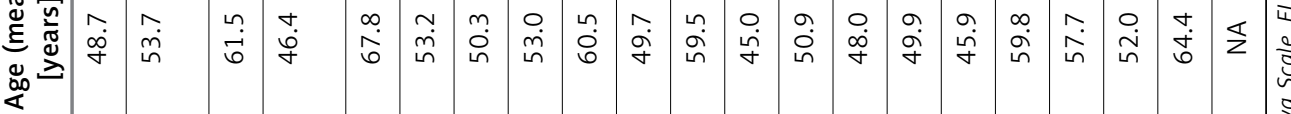

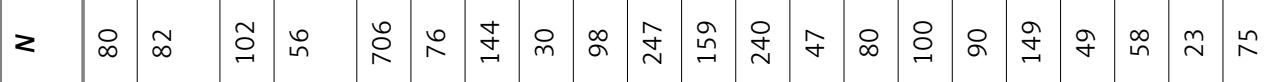

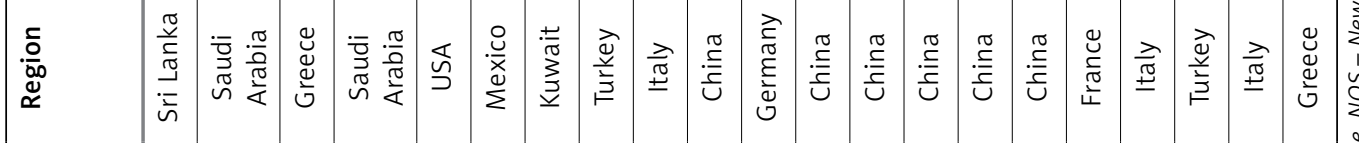

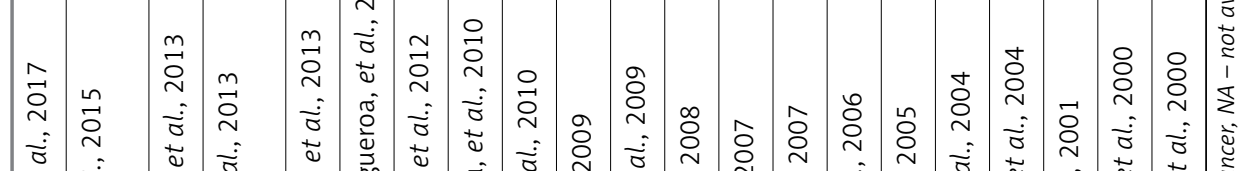

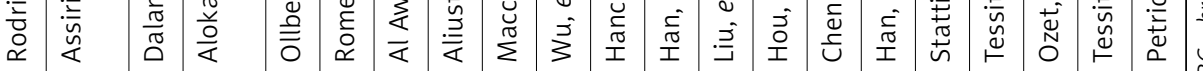


Table II. Basic characteristics of the individual studies of $G$-2548A gene polymorphism included in meta-analysis

\begin{tabular}{|lccccccc|}
\hline First author & Year & Region & \multicolumn{2}{c}{ Numbers } & \multicolumn{2}{c}{ A alleles (\%) } & NOS \\
\cline { 4 - 7 } & & & BC patients & Controls & BC patients & Controls & \\
\hline Rodrigo, et al. & 2017 & Sri Lanka & 80 & 80 & 66.9 & 81.3 & 8 \\
\hline Karakus, et al. & 2015 & Turkey & 199 & 185 & 51.0 & 51.9 & 8 \\
\hline Mahmoudi, et al. & 2015 & Iran & 45 & 41 & 72.2 & 64.6 & 6 \\
\hline Rostami, et al. & 2015 & Iran & 203 & 171 & 72.4 & 59.4 & 8 \\
\hline Mohammadzadeh, et al. & 2015 & Iran & 100 & 100 & 63.5 & 74.5 & 7 \\
\hline Cleveland, et al. & 2010 & USA & 996 & 1101 & 44.2 & 41.8 & 8 \\
\hline Snoussi, et al. & 2006 & Tunisia & 308 & 222 & 36.7 & 27.3 & 8 \\
\hline Total & & & 1931 & 1900 & 49.3 & 46.6 & \\
\hline
\end{tabular}

$O R$ - odds ratio, $\mathrm{Cl}$ - confidence interval.

suggested no publication bias in our analysis $(p=$ 0.985) (Figure 4 B).

Publication bias for leptin G-2548A gene polymorphisms was not detected among the pooled studies $(p=0.968)$ (Figure 5).

\section{Discussion}

Leptin, as a peptide hormone, is mainly synthesized and secreted by adipose tissue. Although leptin has been recognized as a hormonal signal for regulating energy homoeostasis, available evidence demonstrates its multiple physiological functions, such as a metabolic regulator and pro-angiogenic factor [42, 43]. Recently, it has been shown that leptin and its receptor are involved in the processes leading to the initiation and progression of BC. Results from some epidemiologic studies of $B C$ have provided evidence for an association with circulating leptin levels [14, 39]; in addition, several gene polymorphisms have been identified in the human leptin and leptin re-

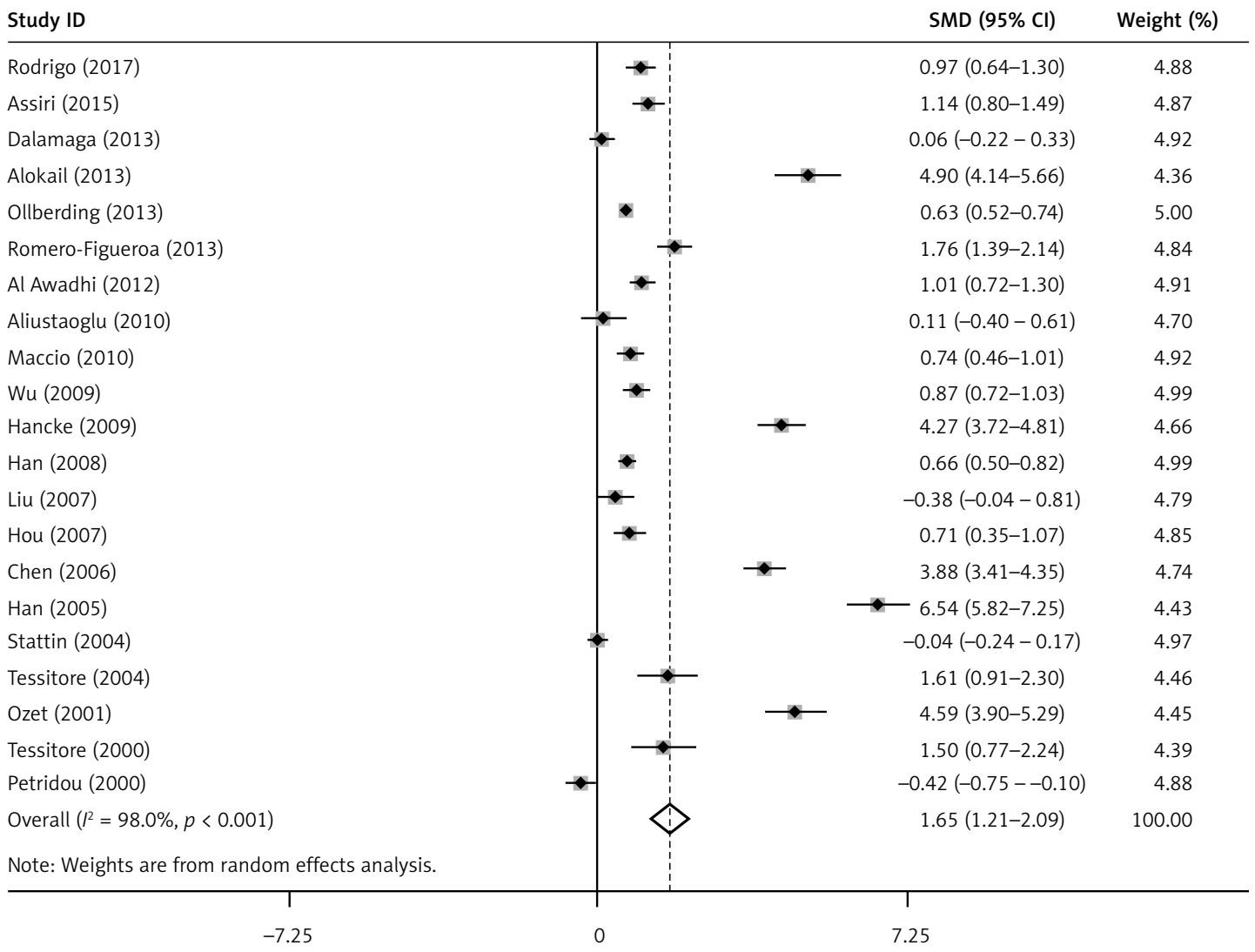

Figure 2. Meta-analysis of 21 studies reporting on leptin in BC patients compared with controls 
Table III. Subgroup analysis of leptin level in BC

\begin{tabular}{|c|c|c|c|c|c|c|c|}
\hline \multirow[t]{2}{*}{ Stratification group } & \multirow[t]{2}{*}{$N$} & \multirow[t]{2}{*}{ SMD $(95 \% \mathrm{Cl})$} & \multicolumn{3}{|c|}{ Heterogeneity test } & \multicolumn{2}{|c|}{ Publication bias } \\
\hline & & & $\mathbf{Q}$ & $P$-value & $I^{2}(\%)$ & $t$ & $P$-value \\
\hline Total & 21 & $1.65(1.21-2.09)$ & 1009.16 & $<0.001$ & 98.00 & 3.09 & 0.006 \\
\hline \multicolumn{8}{|l|}{ Region: } \\
\hline Asia & 7 & $1.95(1.08-2.81)$ & 405.06 & $<0.001$ & 98.50 & 10.78 & 0.095 \\
\hline Arabia & 3 & $2.30(0.71-3.89)$ & 91.14 & $<0.001$ & 97.80 & 16.49 & 0.096 \\
\hline America & 2 & $1.18(0.07-2.29)$ & 32.48 & $<0.001$ & 96.90 & 8.28 & - \\
\hline Europe & 9 & $1.35(0.47-2.23)$ & 407.27 & $<0.001$ & 98.00 & 11.04 & 0.039 \\
\hline Overall & 21 & $1.65(1.21-2.09)$ & 1009.16 & $<0.001$ & 98.00 & 3.09 & 0.006 \\
\hline \multicolumn{8}{|l|}{ Race: } \\
\hline Caucasian & 10 & $1.25(0.62-1.89)$ & 410.40 & $<0.001$ & 97.80 & 4.56 & 0.236 \\
\hline Non-Caucasian & 11 & $2.01(1.36-2.67)$ & 519.68 & $<0.001$ & 98.10 & 10.90 & 0.010 \\
\hline Overall & 21 & $1.65(1.21-2.09)$ & 1009.16 & $<0.001$ & 98.00 & 3.09 & 0.006 \\
\hline \multicolumn{8}{|l|}{ BMI: } \\
\hline$<25$ & 7 & $1.43(0.71-2.16)$ & 160.06 & $<0.001$ & 96.30 & 3.95 & 0.355 \\
\hline $25-30$ & 9 & $1.87(1.15-2.59)$ & 621.03 & $<0.001$ & 98.70 & 9.56 & 0.068 \\
\hline$>30$ & 3 & $2.51(0.88-4.15)$ & 89.53 & $<0.001$ & 97.80 & 16.47 & 0.017 \\
\hline Overall & 19 & $1.80(1.33-2.27)$ & 951.18 & $<0.001$ & 98.10 & 3.39 & 0.003 \\
\hline \multicolumn{8}{|l|}{ WC: } \\
\hline$<80 \mathrm{~cm}$ & 3 & $0.90(0.71-1.09)$ & 3.07 & 0.215 & 34.90 & 0.52 & 0.871 \\
\hline$\geq 80 \mathrm{~cm}$ & 5 & $1.60(0.73-2.46)$ & 171.25 & $<0.001$ & 97.70 & 10.45 & 0.132 \\
\hline Overall & 8 & $1.29(0.81-1.76)$ & 175.05 & $<0.001$ & 96.00 & 1.93 & 0.02 \\
\hline \multicolumn{8}{|l|}{ Measurement type: } \\
\hline ELISA & 14 & $1.64(1.12-2.15)$ & 601.31 & $<0.001$ & 97.80 & 7.64 & 0.020 \\
\hline RIA & 7 & $1.69(0.67-2.70)$ & 406.10 & $<0.001$ & 98.50 & 7.69 & 0.215 \\
\hline Overall & 21 & $1.65(1.21-2.09)$ & 1009.16 & $<0.001$ & 98.00 & 3.09 & 0.006 \\
\hline
\end{tabular}

$B C$ - breast cancer, $B M I$ - body mass index, WC - waist circumference, SMD - standardized mean difference, ELISA - enzyme-linked immunosorbent assay, RIA - radioimmunoassay.

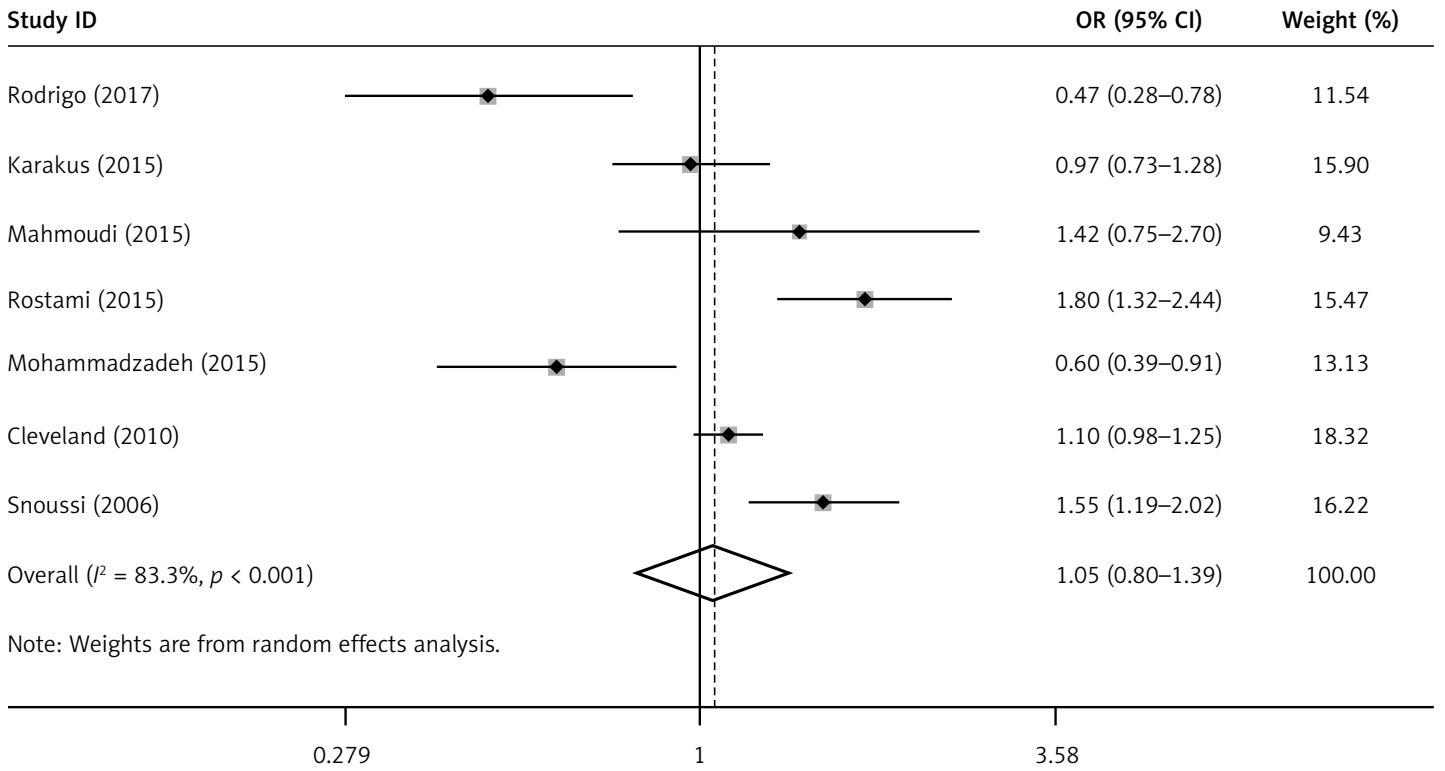

Figure 3. ORs and $95 \% \mathrm{Cl}$ of individual studies and pooled data for the allelic associations between the leptin G-2548A gene polymorphism and BC 
Table IV. Meta-analysis of the association between leptin G-2548A gene polymorphisms and BC

\begin{tabular}{|c|c|c|c|c|c|c|c|c|}
\hline \multirow[t]{2}{*}{ Polymorphism } & \multirow[t]{2}{*}{ Population } & \multirow{2}{*}{$\begin{array}{l}\text { No. of } \\
\text { studies }\end{array}$} & \multicolumn{3}{|c|}{ Test of association } & \multicolumn{3}{|c|}{ Test of heterogeneity } \\
\hline & & & OR & $95 \% \mathrm{Cl}$ & $P$-value & Model & $I^{2}$ & $P$-value \\
\hline $\begin{array}{l}\text { Leptin } G-2548 A \\
\text { A vs. G }\end{array}$ & Overall & 7 & 1.05 & $0.80-1.39$ & 0.722 & $\mathrm{R}$ & $83.3 \%$ & $<0.001$ \\
\hline $\begin{array}{l}\text { AA + AG vs. GG } \\
\text { (dominant) }\end{array}$ & Overall & 7 & 1.07 & $0.78-1.46$ & 0.683 & $\mathrm{R}$ & $57.4 \%$ & 0.029 \\
\hline $\begin{array}{l}\text { AA vs. GG + AG } \\
\text { (recessive) }\end{array}$ & Overall & 7 & 0.85 & $0.53-1.38$ & 0.513 & $\mathrm{R}$ & $85.6 \%$ & $<0.001$ \\
\hline AA vs. GG & Overall & 7 & 1.23 & $0.75-1.99$ & 0.414 & $R$ & $69.3 \%$ & 0.003 \\
\hline
\end{tabular}

$B C$ - breast cancer, $O R$ - odds ratio, $C I$ - confidence interval, $R$ - random model.

Table V. Prevalence of A allele of leptin G-2548A gene polymorphism

\begin{tabular}{|c|c|c|c|c|c|}
\hline \multirow[t]{2}{*}{ Population } & \multirow[t]{2}{*}{ No. of studies } & \multicolumn{2}{|c|}{ Numbers } & \multicolumn{2}{|c|}{ A allele (\%) } \\
\hline & & BC patients & Controls & BC patients & Controls \\
\hline Asia & 4 & 428 & 392 & 69.3 & 81.3 \\
\hline America & 1 & 996 & 1101 & 44.2 & 41.8 \\
\hline Africa & 1 & 308 & 222 & 36.7 & 27.3 \\
\hline Europe & 1 & 199 & 185 & 51.0 & 51.9 \\
\hline Overall & 7 & 1931 & 1900 & 49.3 & 46.6 \\
\hline
\end{tabular}

$B C$ - breast cancer.

A

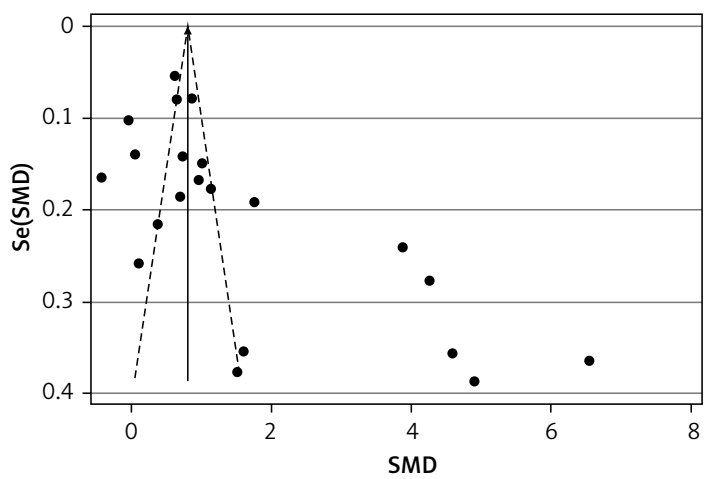

B

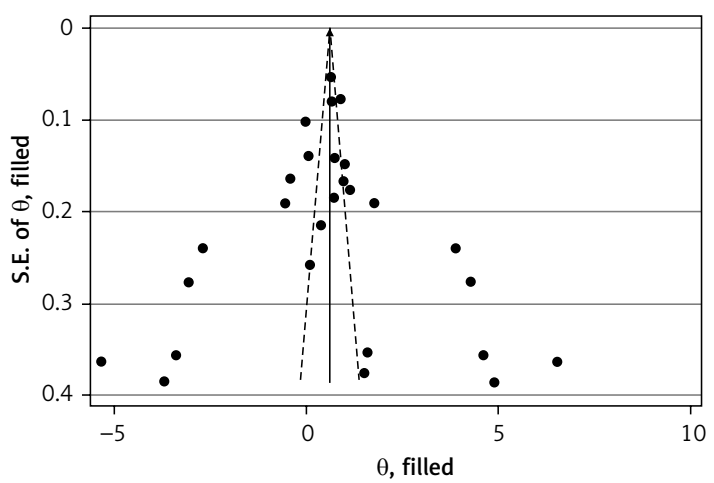

Figure 4. Funnel plot (with pseudo $95 \%$ confidence intervals) with the standard error of the leptin difference plotted against the mean difference of leptin of each study (A); Filled funnel plot (with pseudo 95\% confidence intervals) with the standard error of the leptin difference plotted against the mean difference of leptin of each study (B)

ceptor, such as leptin G-2548A (rs7799039), leptin receptor $Q 223 R / G \ln 223 A r g A>G($ rs1137101) and K109R/Lys109Arg A>G (rs1137100), which were reported to increase risk of $B C$ in some but not in other studies [15, 18, 34, 41, 44].

In the current meta-analysis, we systemically reviewed the data from 27 comparisons of $B C$ patients versus normal controls. The results of circulating leptin levels revealed that BC patients have a statistically significantly higher leptin level than in normal controls; however, there was no association between the leptin G-2548A gene polymorphism and $B C$. The heterogeneity test showed significant heterogeneity among included studies. Heterogeneity refers to the degree of difference

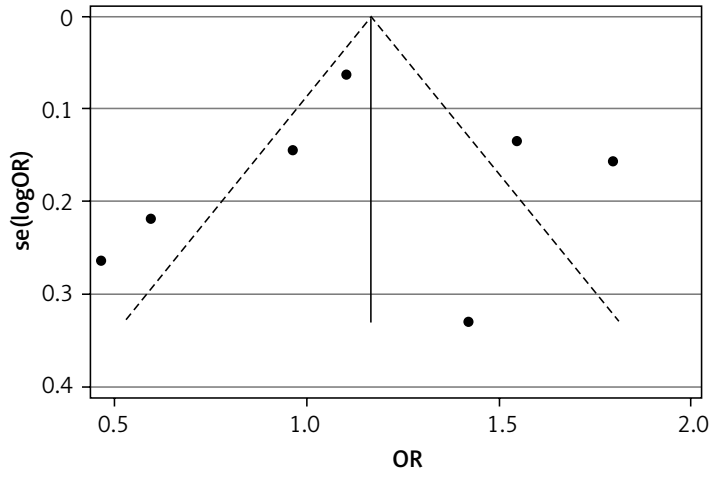

Figure 5. Funnel plot of 7 studies regarding the association between the leptin G-2548A allele and BC in all subjects 
in results among included studies. Strong heterogeneity could lead to an impaired result of metaanalysis and decrease the validity when assessing the pooled estimation. To find possible sources of between-study heterogeneity and other positive factors, subgroup analysis was conducted. Based on the stratification of region, race, BMI, WC and measurement type, no significant change in leptin level was observed in BC patients, and all subgroups showed higher leptin levels in BC patients compared to healthy controls. Among them, the Arabian group had a higher leptin level than other regional groups, Caucasians had a lower leptin level than non-Caucasians, and the BMI > $30 \mathrm{~kg} /$ $\mathrm{m}^{2}$ group had a higher leptin level than the other two groups, which is consistent with previous reports indicating that BMI was inversely correlated with premenopausal cancer risk, including BC [45]. The $W C \geq 80 \mathrm{~cm}$ group had a higher leptin level than the WC $<80 \mathrm{~cm}$ group. WC is an indicator of central obesity. It has been demonstrated that an increased WC level is closely corrected with $\mathrm{BC}$ risk in both premenopausal and postmenopausal populations [46]. Obesity, as reflected by increased BMI, has a strong positive association with postmenopausal BC and an inverse correlation with premenopausal cancer risk, especially associated with increased risk of more aggressive BC. Obese women are likely to have metastatic BC when they are first diagnosed and to have a poor prognosis regardless of their menopausal status. Central obesity, mainly measured by the WC or waist-hip ratio (WHR), can increase $B C$ risk in both premenopausal and postmenopausal populations. Furthermore, BC patients with over-expression of leptin show a lower survival rate. Thus, for BC patients, maintaining a healthy weight may be beneficial for a good disease prognosis.

The different results of subgroup analyses may be influenced by geographic location, ethnic variations and medical/health conditions. However, we cannot exclude the possibility that the different clinical characteristics, disease durations and age may contribute to a positive result.

Although our meta-analysis included relatively high-quality studies, there were still several limitations. First, comparison among all the included studies showed significant heterogeneity and there may have been publication bias. Second, only data from three databases were collected and the number and sample of included studies were relatively small and insufficient, especially for gene polymorphism, which may also affect the reliability of the analysis results. Third, the data on circulating leptin levels in several studies were approximate numbers, and might be biased compared with the actual number. Fourth, this review only included studies published in English, which would inevitably cause language bias.
Regardless of these four limitations, it is worth emphasizing some strengths of this study. Compared to individual studies, our study could provide a pooled result of leptin level and give an accurate evaluation of the relationship between leptin levels and $\mathrm{BC}$, as well as the association between the leptin $G-2548$ A gene polymorphism and $\mathrm{BC}$.

In conclusion, our findings suggest that circulating leptin level is elevated in BC patients, thereby suggesting that an elevated leptin level may be a factor for BC. However, we did not observe any association between leptin G-2548A gene polymorphism and BC susceptibility. Further studies are necessary to determine the role of leptin levels and its gene polymorphisms in the pathogenesis of $B C$.

\section{Conflict of interest}

The authors declare no conflict of interest.

\section{References}

1. Pignatelli M, Cocca C, Santos A, Perez-Castillo A. Enhancement of BRCA1 gene expression by the peroxisome proliferator-activated receptor gamma in the MCF-7 breast cancer cell line. Oncogene 2003; 22: 5446-50.

2. Housa D, Housova J, Vernerova Z, Haluzik M. Adipocytokines and cancer. Physiol Res 2006; 55: 233-44.

3. Carrasco E, Garrido JM, Alvarez PJ, et al. Meroxest improves the prognosis of immunocompetent C57BL/6 mice with allografts of E0771 mouse breast tumor cells. Arch Med Sci 2016; 12: 919-27.

4. Nowikiewicz T, Wnuk P, Malkowski B, Kurylcio A, Kowalewski J, Zegarski W. Application of artificial neural networks for predicting presence of non-sentinel lymph node metastases in breast cancer patients with positive sentinel lymph node biopsies. Arch Med Sci 2017; 13: 1399-407.

5. Wang XJ, Yuan SL, Lu Q et al. Potential involvement of leptin in carcinogenesis of hepatocellular carcinoma. World J Gastroenterol 2004; 10: 2478-81.

6. Russo VC, Metaxas S, Kobayashi K, Harris M, Werther GA. Antiapoptotic effects of leptin in human neuroblastoma cells. Endocrinology 2004; 145: 4103-12.

7. O’Brien SN, Welter BH, Price TM. Presence of leptin in breast cell lines and breast tumors. Biochem Biophys Res Commun 1999; 259: 695-8.

8. Ishikawa M, Kitayama J, Nagawa H. Enhanced expression of leptin and leptin receptor (OB-R) in human breast cancer. Clin Cancer Res 2004; 10: 4325-31.

9. Hu X, Juneja SC, Maihle NJ, Cleary MP. Leptin: a growth factor in normal and malignant breast cells and for normal mammary gland development. J Natl Cancer Inst 2002; 94: 1704-11.

10. Yin $\mathrm{N}$, Wang D, Zhang $\mathrm{H}$, et al. Molecular mechanisms involved in the growth stimulation of breast cancer cells by leptin. Cancer Res 2004; 64: 5870-5.

11. Tessitore L, Vizio B, Pesola D, et al. Adipocyte expression and circulating levels of leptin increase in both gynaecological and breast cancer patients. Int J Oncol 2004; 24: 1529-35. 
12. Chen DC, Chung YF, Yeh YT, et al. Serum adiponectin and leptin levels in Taiwanese breast cancer patients. Cancer Lett 2006; 237: 109-14.

13. Mantzoros CS, Bolhke K, Moschos S, Cramer DW. Leptin in relation to carcinoma in situ of the breast: a study of pre-menopausal cases and controls. Int J Cancer 1999; 80: 523-6.

14. Stattin P, Soderberg S, Biessy C, et al. Plasma leptin and breast cancer risk: a prospective study in northern Sweden. Breast Cancer Res Treat 2004; 86: 191-6.

15. Snoussi K, Strosberg AD, Bouaouina N, Ben Ahmed S, Helal AN, Chouchane L. Leptin and leptin receptor polymorphisms are associated with increased risk and poor prognosis of breast carcinoma. BMC Cancer 2006; 6: 38.

16. Rostami S, Kohan L, Mohammadianpanah M. The LEP $\mathrm{G}-2548 \mathrm{~A}$ gene polymorphism is associated with age at menarche and breast cancer susceptibility. Gene 2015; 557: 154-7.

17. Rodrigo C, Tennekoon KH, Karunanayake EH, De Silva K, Amarasinghe I, Wijayasiri A. Circulating leptin, soluble leptin receptor, free leptin index, visfatin and selected leptin and leptin receptor gene polymorphisms in sporadic breast cancer. Endocr J 2017; 64: 393-401.

18. Mahmoudi R, Noori Alavicheh B, Nazer Mozaffari MA, Fararouei $M$, Nikseresht $M$. Polymorphisms of leptin $(-2548 \mathrm{G} / \mathrm{A})$ and leptin receptor (Q223R) genes in Iranian women with breast cancer. Int J Genomics 2015; 2015: 132720.

19. Karakus N, Kara N, Ulusoy AN, Ozaslan C, Tural S, Okan I. Evaluation of CYP17A1 and LEP gene polymorphisms in breast cancer. Oncol Res Treat 2015; 38: 418-22.

20. Higgins JP, Thompson SG, Deeks JJ, Altman DG. Measuring inconsistency in meta-analyses. BMJ 2003; 327: 557-60.

21. Higgins JP, Thompson SG. Quantifying heterogeneity in a meta-analysis. Stat Med 2002; 21: 1539-58.

22. Egger M, Davey Smith G, Schneider M, Minder C. Bias in meta-analysis detected by a simple, graphical test. BMJ 1997; 315: 629-34.

23. Assiri AM, Kamel HF, Hassanien MF. Resistin, visfatin, adiponectin, and leptin: risk of breast cancer in pre- and postmenopausal Saudi females and their possible diagnostic and predictive implications as novel biomarkers. Dis Markers 2015; 2015: 253519.

24. Dalamaga M, Karmaniolas K, Papadavid E, Pelekanos N, Sotiropoulos G, Lekka A. Hyperresistinemia is associated with postmenopausal breast cancer. Menopause 2013; 20: 845-51.

25. Alokail MS, Al-Daghri N, Abdulkareem A, et al. Metabolic syndrome biomarkers and early breast cancer in Saudi women: evidence for the presence of a systemic stress response and/or a pre-existing metabolic syndromerelated neoplasia risk? BMC Cancer 2013; 13: 54.

26. Ollberding NJ, Kim Y, Shvetsov YB, et al. Prediagnostic leptin, adiponectin, C-reactive protein, and the risk of postmenopausal breast cancer. Cancer Prev Res (Phila) 2013; 6: 188-95.

27. Romero-Figueroa Mdel S, Garduno-Garcia Jde J, Duarte-Mote J, Matute-Gonzalez G, Gomez-Villanueva A, De la Cruz-Vargas J. Insulin and leptin levels in obese patients with and without breast cancer. Clin Breast Cancer 2013; 13: 482-5.

28. Al Awadhi SA, Al Khaldi RM, Al Rammah T, Kapila K, Mojiminiyi OA. Associations of adipokines and insulin resistance with sex steroids in patients with breast cancer. Indian J Med Res 2012; 135: 500-5.
29. Aliustaoglu M, Bilici A, Gumus $M$, et al. Preoperative serum leptin levels in patients with breast cancer. Med Oncol 2010; 27: 388-91.

30. Maccio A, Madeddu C, Gramignano G, et al. Correlation of body mass index and leptin with tumor size and stage of disease in hormone-dependent postmenopausal breast cancer: preliminary results and therapeutic implications. J Mol Med (Berl) 2010; 88: 677-86.

31. Wu MH, Chou YC, Chou WY, et al. Circulating levels of leptin, adiposity and breast cancer risk. $\mathrm{Br} J$ Cancer 2009; 100: 578-82.

32. Hancke K, Grubeck D, Hauser N, Kreienberg R, Weiss JM. Adipocyte fatty acid-binding protein as a novel prognostic factor in obese breast cancer patients. Breast Cancer Res Treat 2009; 119: 367-77.

33. Han CZ, Du LL, Jing JX, et al. Associations among lipids, leptin, and leptin receptor gene Gin223Arg polymorphisms and breast cancer in China. Biol Trace Elem Res 2008; 126: 38-48.

34. Liu CL, Chang YC, Cheng SP, et al. The roles of serum leptin concentration and polymorphism in leptin receptor gene at codon 109 in breast cancer. Oncology 2007; 72: 75-81.

35. Hou WK, Xu YX, Yu T, et al. Adipocytokines and breast cancer risk. Chin Med J (Engl) 2007; 120: 1592-6.

36. Han C, Zhang HT, Du L, et al. Serum levels of leptin, insulin, and lipids in relation to breast cancer in China. Endocrine 2005; 26: 19-24.

37. Ozet A, Arpaci F, Yilmaz MI, et al. Effects of tamoxifen on the serum leptin level in patients with breast cancer. Jpn J Clin Oncol 2001; 31: 424-7.

38. Tessitore L, Vizio B, Jenkins $\mathrm{O}$, et al. Leptin expression in colorectal and breast cancer patients. Int J Mol Med 2000; 5: 421-6.

39. Petridou E, Papadiamantis Y, Markopoulos C, Spanos E, Dessypris N, Trichopoulos D. Leptin and insulin growth factor I in relation to breast cancer (Greece). Cancer Causes Control 2000; 11: 383-8.

40. Mohammadzadeh G, Ghaffari MA, Bafandeh A, Hosseini SM, Ahmadi B. The relationship between -2548 $\mathrm{G} / \mathrm{A}$ leptin gene polymorphism and risk of breast cancer and serum leptin levels in Ahvazian women. Iran J Cancer Prev 2015; 8: 100-8.

41. Cleveland RJ, Gammon MD, Long CM, et al. Common genetic variations in the LEP and LEPR genes, obesity and breast cancer incidence and survival. Breast Cancer Res Treat 2010; 120: 745-52.

42. Biesiada LA, Glowacka E, Krekora M, Sobantka S, Krokocka A, Krasomski G. The impact of excessive maternal weight on the nutritional status of the fetus - the role of leptin. Arch Med Sci 2016; 12: 394-401.

43. Begenik H, Aslan M, Dulger AC, et al. Serum leptin levels in gastric cancer patients and the relationship with insulin resistance. Arch Med Sci 2015; 11: 346-52.

44. Motawi T, Salman T, Shaker O, Abdelhamid A. Association of polymorphism in adiponectin (+45 T/G) and leptin $(-2548 \mathrm{G} / \mathrm{A})$ genes with type 2 diabetes mellitus in male Egyptians. Arch Med Sci 2015; 11: 937-44.

45. van den Brandt PA, Spiegelman D, Yaun SS, et al. Pooled analysis of prospective cohort studies on height, weight, and breast cancer risk. Am J Epidemiol 2000; 152: 514-27.

46. Calle EE, Thun MJ. Obesity and cancer. Oncogene 2004; 23: 6365-78. 